\title{
Significant change in insulin production, glucose tolerance and ER stress signaling in transgenic mice coexpressing insulin-siRNA and human IDE
}

\author{
DAE YOUN HWANG ${ }^{1}$, SUJIN SEO $^{1}$, YONGKYU KIM $^{1}$, CHUELKYU KIM $^{1}$, SUNBO SHIM $^{1}$, SEUNGWAN JEE $^{1}$, \\ SUHAE LEE ${ }^{1}$, JISOON SIN $^{1}$, JUNYONG CHO ${ }^{2}$, BYEONGCHUEL KANG ${ }^{3}$, INSURK JANG ${ }^{4}$ and JUNGSIK CHO ${ }^{1}$ \\ ${ }^{1}$ Laboratory Animal Resources Team, National Institute of Toxicological Research, Korea FDA, Seoul 122-704; \\ ${ }^{2}$ Exercise Biochemistry Laboratory, Korean National Sports University, Seoul 138-763; ${ }^{3}$ Clinical \\ Research Center, Seoul National University Hospital, Seoul 110-744; ${ }^{4}$ Department of Animal \\ Science and Biotechnology, RAIRC, Jinju National University, Jinju 660-758, Korea
}

Received July 10, 2006; Accepted August 31, 2006

\begin{abstract}
The dual expression system for the suppression and clearance of insulin has not been previously used to produce transgenic mice for diabetes-related disease. The aim of this study was to produce new transgenic mice coexpressing specific insulin small interfering RNA (siRNA) sequences and the human insulin degrading enzyme (hIDE) gene in order to examine the diabetes-like phenotype. To achieve this, a new lineage of transgenic mice was produced by the microinjection of the dual expression constructs ( $\mathrm{pH} 1 / \mathrm{siRNA}_{\text {insulin }}-\mathrm{CMV} / \mathrm{hIDE}$ ) into mouse fertilized eggs. The results showed that overexpressing the insulin siRNA and hIDE genes resulted in the induction of the human enzyme, impaired glucose tolerance and lower serum insulin levels compared to the Non-Tg mice. Moreover, the Tg mice aged 20 weeks had a significantly activated ER stress signaling compared to their Non-Tg counterparts, which may be associated with the suppression of insulin production in the pancreas and the degradation of insulin in the liver, respectively. Therefore, insulin-suppressed transgenic mice can be used to examine diabetes as a new diabetes-like phenotype model, which results in a lower level of circulating insulin without the destruction of pancreatic islets.
\end{abstract}

\section{Introduction}

The suppression of insulin production and the degradation of insulin are very effective areas for the development of new model animals for type I diabetes. Insulin removal helps control the cellular response to hormones by decreasing the

Correspondence to: Dr Dae Youn Hwang, Laboratory Animal Resources Team, National Institute of Toxicological Research, Korea FDA, 5 Nokbun-dong Eunpyung-ku, Seoul 122-704, Korea E-mail: dyhwang@kfda.go.kr

Key words: siRNA, hIDE, insulin, transgenic mice, diabetes substrate availability. The degradation process may also be involved in mediating some aspects of insulin action. Most evidence suggests that an insulin-degrading enzyme is associated with the primary mechanism of insulin degradation, although other systems including PDI, lysosome, and other enzymes undoubtedly contribute to the metabolism of insulin (1). IDE (insulysin, insulinase, EC3.4.24.56) is a member of the M16 family of zinc-metalloendopeptidases containing a tetrad of conserved residues [H-X-X-E-H-X (76)-E] at its catalytic center (1). This protein is broadly expressed in both insulin-sensitive and insulin-insensitive tissues, and is localized mainly in the cytoplasm within the cells. However, different forms of this protein can be secreted into extracellular spaces or associated cell surfaces $(2,3)$. Studies have reported various IDE high-affinity substrates, which were polypeptides 28-51 amino acids in length. A variety of physiological peptides have been shown to be substrates in vitro for IDE including insulin and glucagons (4), the atrial natriuretic factor (5), transforming growth factor $\alpha(6,7)$, the atrial natriuretic peptide (8), $\beta$-endorphin and dynorphins (9), amylin (10), and amyloid $\beta$ peptides $(11,12)$. IDE may also have other biological functions such as the clearance of the $B$-amyloid precursor protein in the intracellular domain (AICD), which is suggested to regulate the transcriptional activity in the nucleus (13). Furthermore, it was demonstrated that IDE interacts directly and enhances the DNA binding of androgen and glucocorticoid receptor fragments in vitro (14). Duckworth et al (15) reported that IDE exists in the cell as a complex with the $26 \mathrm{~S}$ proteasome, which is regarded as the principal site of the uniquitin-dependent intracellular protein. However, no transgenic mice expressing a hIDE protein under the control of the human cytomegalovirus (CMV) immediate early promoter have been produced to study the IDE function in vivo.

Small interfering RNA or double-stranded RNA (dsRNA)based gene silencing is a highly conserved mechanism for sequence-specific post-transcriptional gene silencing between various species $(16,17)$. This technique has been used in the nematode Caenorhabditis elegans to suppress gene expression by an injection of a double-stranded mixture into adult 
animals (18). Furthermore, Bernestein et al (19) identified the new enzyme, Dicer, which produces putative guide RNA. Dicer is a member of the RNase III family of nucleases that specifically cleave double-stranded RNA, and is evolutionally conserved in worms, flies, plants, fungi and mammals. Until recently, siRNA has not been used to silence mammalian genes, since the introduction of dsRNA longer than $30 \mathrm{nt}$ induces a sequence-non-specific viral response (20). However, Elbashir et al (21) suggested that the introduction of short duplexes of synthetic 21-23-nt RNAs into mammalian cells has gene specific silencing effects. Nevertheless, this method has a critical limitation in that the transfected synthetic siRNA works for only a few days in mammalian cells. This problem can be overcome by a vector-based technique for the synthesis of siRNAs, which was driven by the RNA polymerase III promoter $(22,23,24)$. In addition, Hasuwa et al (25) demonstrated that transgenetically supplied siRNA silenced the ubiquitously enhanced expression of green fluorescent protein in all tissues of mice and rats. These effects of gene suppression were transmitted into their progenies containing the expression vector. However, there are no reports as to whether the transgene-based siRNA system can suppress the expression of the insulin gene in adult mice.

This study has developed novel $\mathrm{Tg}$ mice coexpressing siRNA $_{\text {insulin }}$ and hIDE, which induce the suppression of insulin production and the activation of insulin clearance, respectively. In addition, these transgenic mice were shown to have diabetes-like phenotypes such as insulin suppression, impaired glucose tolerance, and an altered ER stress signaling pathway. These results suggest that siRNA insulin $_{\text {-hIDE }}$ transgenic mice may be useful for developing an animal model for diabetes, which show a lower level of insulin in blood without the destruction of pancreatic islets.

\section{Materials and methods}

Plasmid construction. In an attempt to suppress insulin production in $\mathrm{Tg}$ mice, the siRNA sequences of 5 types were selected from the open reading frame of the rat insulin cDNA sequence using the siRNA target finder program (Ambion, USA). The transcription-based siRNA vector was constructed using the Silencer siRNA construction kit (cat. no. 5770, Ambion). Each siRNA duplex of 5 types was ligated into the BamHI and HindIII sites under the control of the H1 promoter on the pSilencer 3.1-H1 neo vectors. The resulting plasmid, named $p H 1 / s i R N A_{\text {insulin }}$, was verified for the presence and orientation of the siRNA duplex using an automatic sequencer (ABI 373; Perkin Elmer, USA). The $p H 1 /$ siRNA ${ }_{\text {insulin }}$ fragment was amplified by a polymerase chain reaction (PCR) with the specific primers (sense; 5'-CGA TTA ATG TTC CCA GTC ACG AC-3' and antisense; 5-'CGA TTA ATG AGT TAG CTC ACT CAT TAG GC-3') from the $p H 1 /$ siRNA $A_{\text {insulin }}$ vector, and then ligated into the AseI site in the $p E G M-T$ vector $\left(p H 1 /\right.$ siRNA $\left.A_{\text {insulin }}\right)$.

In order to overexpress the hIDE protein, hIDE cDNA was amplified by PCR using the cDNA from the total RNA of the human HepG2 liver cell line. This reaction was achieved using specific primers: sense; 5'-CGA CCG GTG ACT GCG CTG GCT AAT GCG GTA-3' and antisense; 5'-GCT CTA
GAC TTC AGA GTT TTG CAG CCA TGA AG-3', which correspond with nucleotides 44-65 and 3096-3119 of the IDE gene, with 25 cycles of the following: $95^{\circ} \mathrm{C}$ for $30 \mathrm{sec}$ for denaturation, $62^{\circ} \mathrm{C}$ for $30 \mathrm{sec}$ for annealing and $72^{\circ} \mathrm{C}$ for $45 \mathrm{sec}$ for extension. The 3,080-bp products of the amplified IDE sequence in length were cloned into the $p G E M-T$ vector (Promega A3600). The IDE fragment (3,080-bp) was obtained by digesting $p G E M-h I D E$ with $A g e \mathrm{I} / S a c I I$ enzymes, and cloning them into the AgeI/SacII site of pEGFP C-1 ( $p C M V /$ hIDE) (Fig. 2).

Finally, the dual expression vector involving $\mathrm{pH} / \mathrm{l}$ siRNA $_{\text {insulin }}$ and $p C M V / h I D E$ were constructed by cloning the $\mathrm{H} 1 / \mathrm{siRNA}_{\text {insulin }}$ fragment into the AseI site of $p C M V / h I D E$. The resulting plasmid, named $\mathrm{pH} 1 / \mathrm{siRNA}_{\text {insulin }}-\mathrm{CMV} / \mathrm{hIDE}$, was verified for the presence and orientation of the siRNA duplex by an automatic sequencer (ABI 373, Perkin Elmer).

Production of transgenic mice. The $\mathrm{pH} 1 / \mathrm{siRNA}_{\mathrm{insulin}}-\mathrm{CMV} /$ hIDE plasmid was digested with $B \ln \mathrm{I}$ in order to remove the prokaryotic sequence, and was then electrophoresized in an agarose gel. The linear gene fragment of the $\mathrm{pH} 1 / \mathrm{siRNA}_{\text {insulin }}{ }^{-}$ CMV/hIDE fragment (6.214-kb) was excised and extracted from the agarose gel. The $\mathrm{pH} 1 / \mathrm{siRNA}_{\text {insulin }}-\mathrm{CMV} / \mathrm{hIDE}$ fragment was purified by electropurification, diluted to $4 \mathrm{ng} / \mu \mathrm{l}$ and microinjected into the male pronucleus of the fertilized embryos, which were obtained by crossing C57BL/6 (female) mice with DBA2 (male) mice. The injected eggs were then transferred into the oviducts of a pseudopregnant ICR recipient female.

Maintenance of mice. All of the mice were kept in an accredited Korean FDA animal facility in accordance with the AAALAC International Animal Care policies (Accredited Unit, Korean Food and Drug Administration, unit no. 000996). The mice were given a standard irradiated chow diet (Purina Mills Inc.) ad libitum, and were maintained in a specified pathogen-free state under a strict light cycle (light on at 06:00 h and off at 18:00 h). All pedigrees were hemizygous for their transgene.

Southern blot analysis of the transgene inserted in genomic $D N A$. The presence of the inserted transgene was determined from the genomic DNA extracted from the tail of the 4-weekold founder mice, and the transgenes were detected by Southern blot analysis of the HindIII-digested tail DNA. After electrophoresis, the DNA was transferred overnight to nylon membranes in 10X SSC according to the manufacturer's instructions. The membranes were then immersed in $0.4 \mathrm{~N}$ $\mathrm{NaOH}$, neutralized in 0.2 M Tris- $\mathrm{HCl}(\mathrm{pH} 7.5)$ and $2 \mathrm{X}$ SSC, and then allowed to air dry. Each membrane was prehybridized at $65^{\circ} \mathrm{C}$ for $2 \mathrm{~h}$ in a hybridization buffer. The ${ }^{32} \mathrm{P}$-labeled siRNA-hIDE probe was added to the membranes, and hybridization was allowed to proceed at $65^{\circ} \mathrm{C}$ for $18 \mathrm{~h}$. The membranes were then washed using the following procedure: $15 \mathrm{~min}$ in $2 \mathrm{X} \mathrm{SSC} / 0.2 \% \mathrm{SDS}$ at room temperature (once); $15 \mathrm{~min}$ in $1 \mathrm{x} \mathrm{SSC} / 0.2 \% \mathrm{SDS}$ at $65^{\circ} \mathrm{C}$ (three times) and $30 \mathrm{~min}$ in $0.5 \mathrm{X} \mathrm{SSC} / 0.2 \% \mathrm{SDS}$ at $65^{\circ} \mathrm{C}$ (three times). The filters were then exposed to Kodak X-ray film at $-70^{\circ} \mathrm{C}$. The hybridization signal was quantified using a GS-690 imaging densitometer (Biorad, USA). 
PCR analysis. The transgene was identified by DNA-PCR analysis of the genomic DNA that had been isolated from the tails of the 4-week-old founder mice. This transgene DNA was synthesized using the sense and antisense primers, 5'GGT TTT CCC AGT CAC GAC-3 and 5'-GAG TTA GCT CAC YCA TAG GC-3, respectively, with a complementary siRNA $A_{\text {insulin }}$ - $h I D E$ plasmid ranging from 359-376 and 663-683 nucleotides as the DNA template. After 25 cycles of amplification, the level of the $s i R N A_{\text {insulin }}$-hIDE product (324-bp) was quantified using a Kodak electrophoresis documentation and analysis system 120 on 1\% agarose gels. For RT-PCR analysis, each tissue sample was frozen in liquid nitrogen. The frozen tissues were chopped with scissors and homogenized in an RNAzol B solution (CS104, Tet-Test Inc.). The isolated RNA was then determined by UV-spectroscopy. The expression of the transgenes was examined using RT-PCR with $5 \mu \mathrm{g}$ of the total RNA from each tissue. Oligo-dT primer [Gibco BRL (18418-012)] (500 ng) was annealed at $70^{\circ} \mathrm{C}$ for $10 \mathrm{~min}$. The complementary DNA, which served as the template for further amplification, was synthesized by adding dATP, dCTP, dGTP and dTTP with 200 units of reverse transcriptase. Ten pmole of the sense and antisense primers were then added, and the reaction mixture was subjected to 28 cycles of amplification. Amplification was carried out in a Perkin-Elmer thermal cycler using the following cycles: $30 \mathrm{sec}$ at $94^{\circ} \mathrm{C}, 30 \mathrm{sec}$ at $62^{\circ} \mathrm{C}$ and $45 \mathrm{sec}$ at $72^{\circ} \mathrm{C}$. In each case, minus-RT controls were included in order to differentiate the DNA and RNA products. RT-PCR was also performed using the primers specific to B-actin in order to ensure the RNA integrity. The primer sequences for hIDE expression identification were: 5'-GATGC CTGGA GACTC TTTCA AT-3' and 5'-GGTGT TCAGG AAATT CTGGC AAT-3'. Also, the primers for siRNA DNA used for the siRNA expression are as follows: 5'-GGTTT TCCCA GTCAC GAC-3' (sense primer), 5'-GAGTT AGCTC ACTCA TTAGG $\mathrm{C}-3^{\prime}$ (antisense primer). The sequences of the $B$-actin sense and antisense primers were: 5'-TGGAA TCCTG TGGCA TCCAT GAAAC-3' and 5'-TAAAA CGCAG CTCAG TAACA GTCCG-3', respectively. The experiment was repeated three times. All samples were analyzed in triplicate.

Real-time PCR. Real-time PCR analysis was performed using a TaqMan Universal PCR master mix (AB4034437) on an ABI PRISM sequence detection system (ABI-SDS) (Applied Biosystems). After reverse transcription, PCR was carried out in triplicate for each mixture with the synthesized cDNA added to the TaqMan Universal master mix and CYP AdB product (mixture of sense, antisense, and FAM primer). PCR for glyceraldehyde-3-phosphate dehydrogenase (GAPDH), as an endogenous control was performed simultaneously, with the exception of the rodent GAPDH control reagent (AB4308313). TaqMan probes have two fluorescent dyes, one at the 5'-terminal (Reporter, R) for displacing the strand, and the other at the 3'-terminal (Quencher, Q) for blocking the extension. The reaction mixture was then subjected to amplification with the following sequence: 1 cycle at $50^{\circ} \mathrm{C}$ for 2 min (annealing stage), 1 cycle at $95^{\circ} \mathrm{C}$ for $10 \mathrm{~min}$ (denaturation stage) and 40 cycles at $95^{\circ} \mathrm{C}$ for $15 \mathrm{sec}$ and at $60^{\circ} \mathrm{C}$ for $2 \mathrm{~min}$ (extension stage). In all cases, an initial denaturation was carried out at $95^{\circ} \mathrm{C}$ for $5 \mathrm{~min}$ in order to decrease the formation of a primer-dimer complex under these PCR conditions. The ABI-SDS was programmed to take $\mathrm{R}$ and $\mathrm{Q}$ fluorescent dye readings after each cycle at a temperature several degrees $\left(60^{\circ} \mathrm{C}\right)$ lower than the melting temperature of the target amplicon. This step at $60^{\circ} \mathrm{C}$ was taken to avoid, or at least minimize, any potential contribution to the overall fluorescent dye signals from primer-dimer formation. A calibration curve was constructed by plotting the R/Q ratio against the amounts of hIDE and siRNA cDNA synthesized based on the RNA isolated from the livers of the transgenic and non-transgenic mice, which were used as the control.

Glucose tolerance test. The glucose tolerance was determined from five mice/group using an intraperitoneal glucose tolerance test (1.5 mg glucose/g)(IPGTT) after a 24-h fast with blood glucose measurements performed at $0,15,30$, 60,90 and $120 \mathrm{~min}$. A IPGTT study was carried out at 20 weeks of age. The glucose levels in the blood from the Tg and Non$\mathrm{Tg}$ mice were detected with the sensitive strip method using a blood glucose monitoring system (I-sens Co., Korea).

Western blot. The protein prepared from the tissues of the $\mathrm{Tg}$ mice and Non-Tg mice was separated by electrophoresis in a 4-20\% SDS-PAGE gel for $3 \mathrm{~h}$ and transferred to nitrocellulose membranes for $2 \mathrm{~h}$ at $40 \mathrm{~V}$. Each membrane was incubated separately with the primary, anti-IDE (PC730, Calbiochem), anti-JNK (SantaCruz), anti-p-JNK (SantaCruz), anti-eIF2 $\alpha$ antibody (Cell Signaling), anti-p-eIF2 $\alpha$ antibody (Cell Signaling), and anti-actin (A5316, Sigma) antibodies overnight at $4^{\circ} \mathrm{C}$. The membranes were washed with a washing buffer (137 mM NaCl, $2.7 \mathrm{mM} \mathrm{KCl}, 10 \mathrm{mM}$ $\mathrm{Na}_{2} \mathrm{HPO}_{4}, 2 \mathrm{mM} \mathrm{KH} \mathrm{PO}_{4}$ and $0.05 \%$ Tween-20) and incubated with horseradish peroxidase-conjugated goat antirabbit $\operatorname{IgG}$ (Zymed) at a 1:1,000 dilution at room temperature for $2 \mathrm{~h}$. The membrane blots were developed using a chemiluminescent reagent plus kit (ECL, Pharmacia).

The quantification of insulin by ELISA. The level of insulin in the serum from the $\mathrm{Tg}$ and Non-Tg mice was determined using the ultra-sensitive assay procedure and reagents included in the Mercodia rat insulin ELISA kit (cat. no. 101137-01; Mercodia, Sweden). The sera and standards were incubated in antibody-coated plates for $2 \mathrm{~h}$ at room temperature on a plate shaker at 500-600 rpm. The wells were then washed six times using an automatic plate washer (PV100; Hoefer, USA). The HRP conjugate was added to all plates and incubated for $30 \mathrm{~min}$ at room temperature on a shaker. The reaction was terminated with the addition of a $50-\mu 1$ stop solution. The plates were read using a Molecular Devices Vmax plate reader (Sunnyvale, CA, USA) at $450 \mathrm{~nm}$.

Immunohistochemistry. Immunohistochemical analysis was performed as previously described (26). Briefly, the level of IDE protein synthesis was determined using optical microscopy after fixing the tissue samples in 5\% formalin for $12 \mathrm{~h}$, embedding them in paraffin, and slicing them into $4-\mu \mathrm{m}$ thick sections. These sections were de-paraffinized with xylene, rehydrated, and pretreated for $30 \mathrm{~min}$ at room temperature with a PBS-blocking buffer containing $10 \%$ goat 


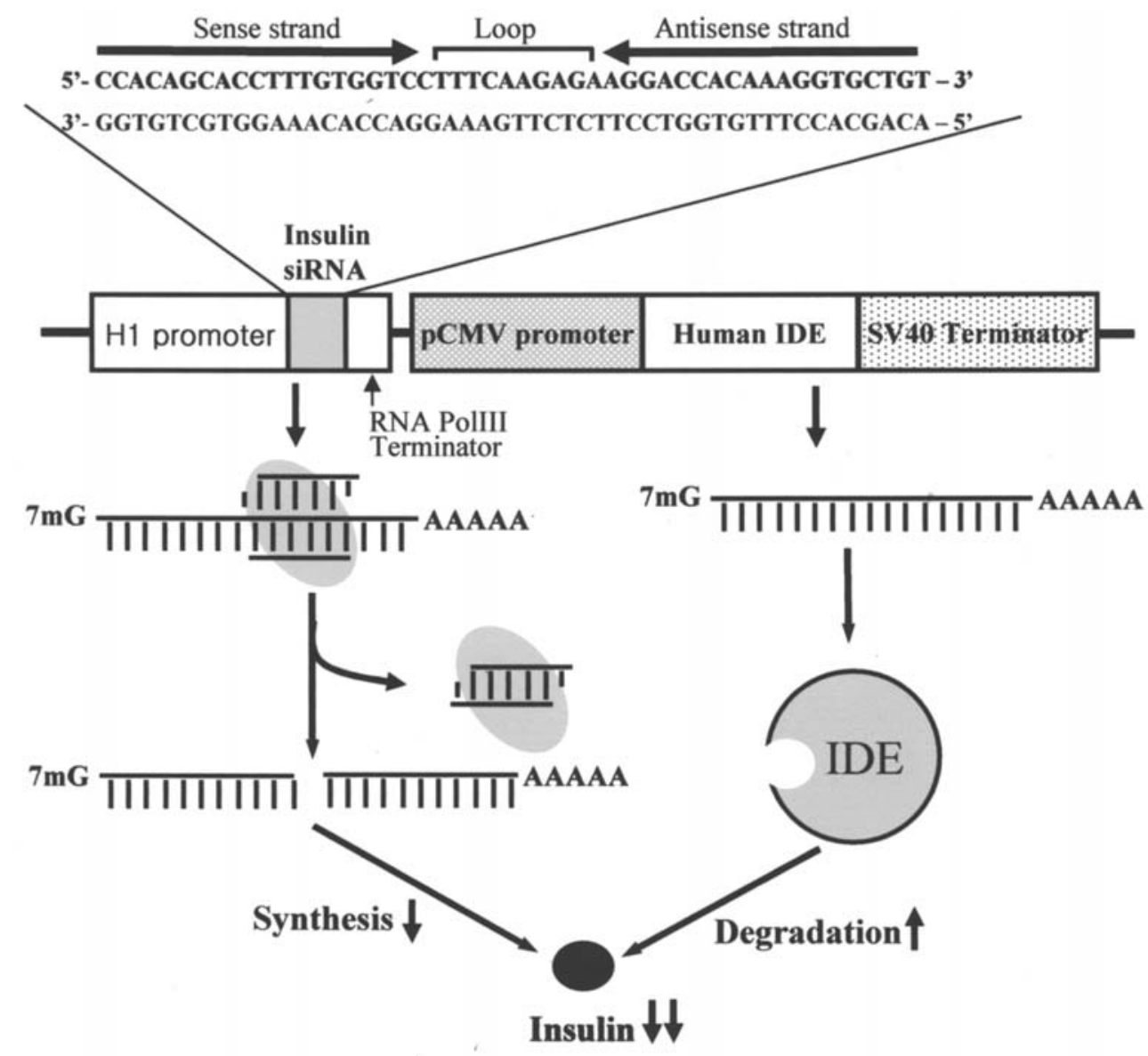

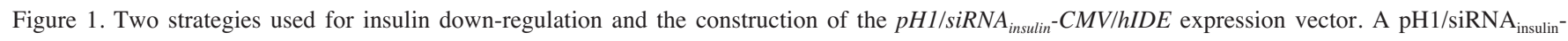
$\mathrm{CMV} / \mathrm{hIDE}$ transgene was constructed based on the dual expression system, which is a transgene-based RNAi system. Two oligonucleotides containing the sense and antisense 21-nt sequence from the insulin coding region, a 9-nt loop sequence, which provided loop structure, were annealed and inserted downstream of the $\mathrm{H} 1$ promoter for expression in various tissues. Human IDE cDNA was cloned into the pCMV/SV40 vector under the control of the CMV promoter. Insulin down-regulation was applied using two strategies, the suppression of insulin production in the pancreas and the stimulation of insulin degradation in all tissues.

A

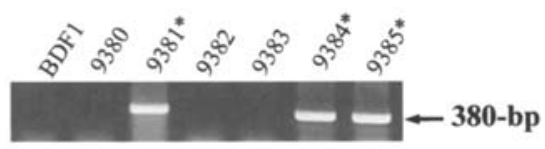

B

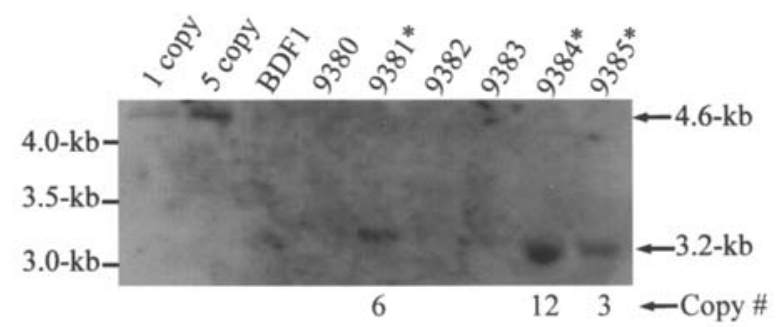

Figure 2. Identification of Tg using PCR and Southern blotting. (A) DNAPCR was performed on the genomic DNA isolated from the tail of a founder mouse, and the resulting products (340 bp) are shown. (B) Ten $\mu \mathrm{g}$ of the tail DNA from the transgenic mice was subjected to Southern blot hybridization. The genomic DNA was digested with EcoRI, and probed with a ${ }^{32} \mathrm{P}$-labeled IDE fragment to detect the integrated transgene. The fragment sizes, as calculated by the relative position of the fragment of a known size in $3.1-\mathrm{kb}$ ( $\lambda$ DNA digested with HindIII/HaeIII), are indicated at the right of the blot. Specific hybridization signals were visualized by autoradiography for 3 days at $-70^{\circ} \mathrm{C}$. serum. The samples were then incubated with the mouse anti-IDE antibody diluted 1:1,000 on a PBS-blocking buffer. These antigen-antibody complexes were visualized with the biotinylated secondary antibody (goat anti-rabbit)-conjugated HRP streptavidin (Histostain-plus kit, Zymed) diluted 1:1,500 in a PBS blocking buffer. The IDE proteins were detected using a stable DAB (ResGen, Invitrogen Corp.) and an imaging densitometer (Model GS-690, Bio-Rad).

Statistical analysis. The tests for significance were performed using a one-way ANOVA test of variance (SPSS for Windows, release 10.10, standard version, Chicago, IL). All of the values are represented as the mean \pm standard deviation (SD). The mean difference between dietary treatments was evaluated at $\mathrm{p}<0.05$.

\section{Results}

A pHI/siRNA $A_{\text {insulin }}$ CMV/hIDE system in transgenic mice. Insulin production was suppressed and insulin degradation was activated in the mice by introducing the $H 1 /$ siRNA ${ }_{\text {insulin }}$ I PolIII fusion gene into the $C M V / h I D E / S V 40$ fusion gene to produce the $\mathrm{pH} 1 / \mathrm{siRNA}_{\text {insulin }}-\mathrm{CMV} / \mathrm{hIDE}$ dual expression 

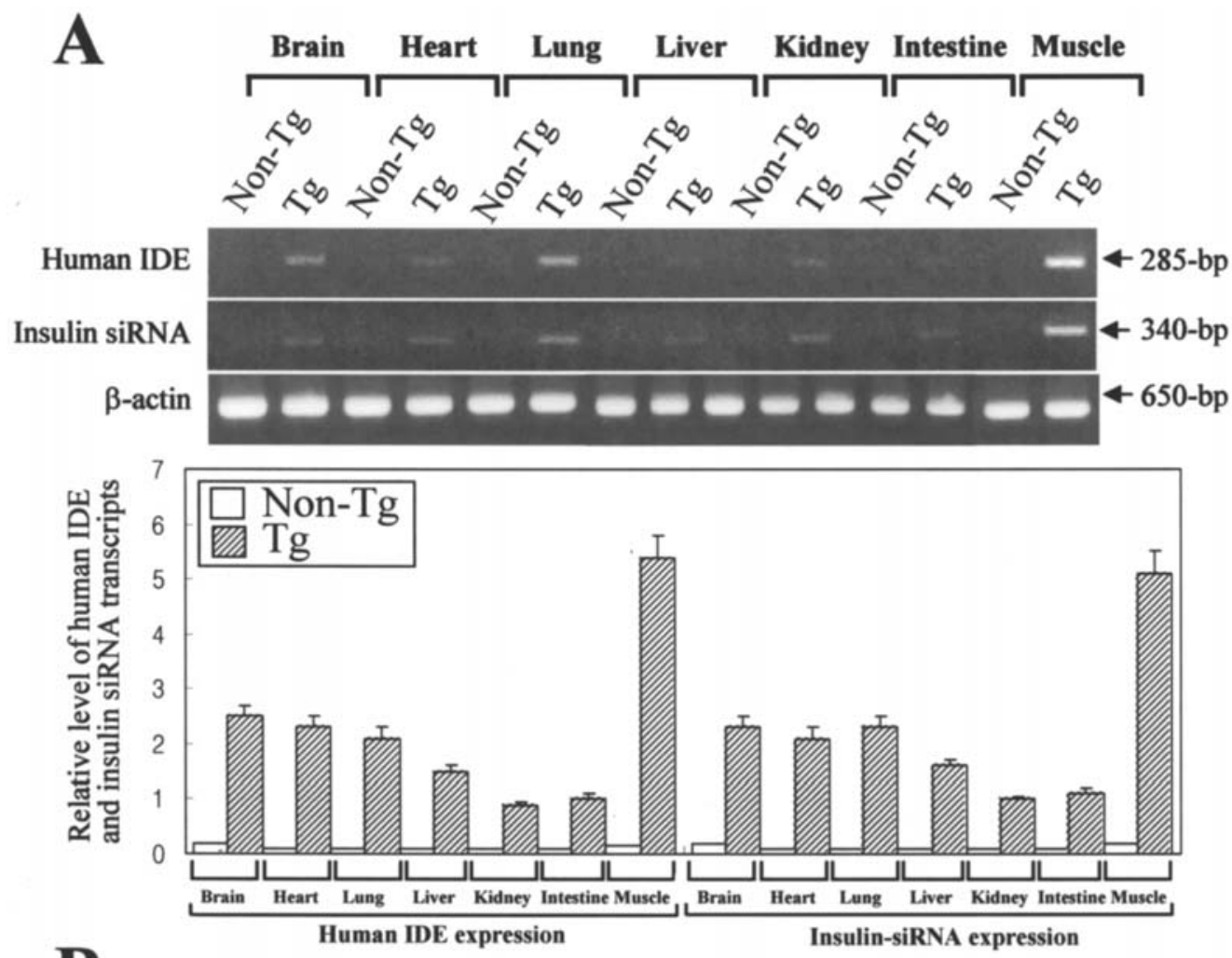

B

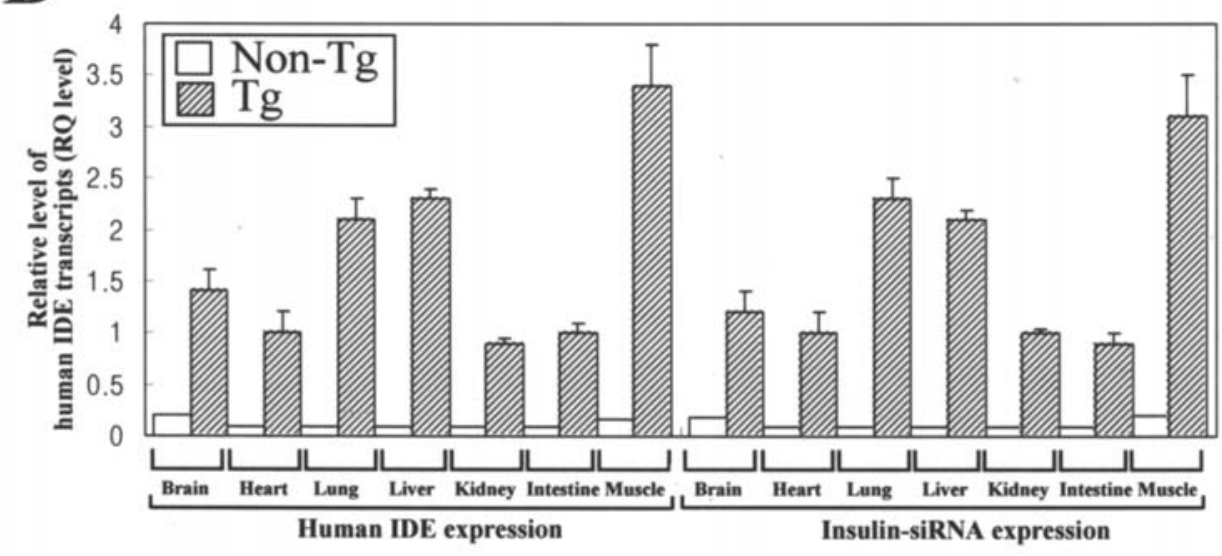

Figure 3. Tissue-specific expression of the IDE transgenes and insulin siRNA in the Tg mice. (A) Expression of IDE in various tissues by RT-PCR. The $B$-actin signal was used as the control, and the transcript (650-bp) indicates the RNA loading. In addition, the RT-PCR products for IDE (340-bp) are indicated. IDE expression in the Non-Tg and the Tg groups is shown. The transcript was quantified using a Kodak electrophoresis documentation and analysis system 120. (B) Real-time PCR analysis of hIDE expression. Calibration was constructed by plotting the R/Q ratio against the amounts of hIDE cDNA synthesized based on the RNA isolated from the tissue of the transgenic mice and from the tissue of the non-transgenic mice used as the control. The data represents the mean \pm SEM from three replicates. ${ }^{*} \mathrm{p}<0.05$, significant difference between treatments.

system (Fig. 1). The H1/siRNA $A_{\text {insulin }}-C M V / h I D E$ fragment (6.214-kb), in which the prokaryotic sequence had been eliminated through the digestion of $p H 1 /$ siRNA $_{\text {insulin }}{ }^{-}$ $C M V / h I D E(7.2-\mathrm{kb})$ with $B \ln \mathrm{I}$, was used for the microinjection. Of a total of 34 offspring (15 males and 19 females), 1 male (\#9381) and 2 females (\#9384, \#9385) of the first lineage founder mice possessed the HI/siRNA insulin CMV/hIDE gene, which was identified by DNA-PCR (Fig. 2A). Also, the intensity and restriction patterns of the DNA obtained from the Southern blotting were compared among Tg mice using a ${ }^{32} \mathrm{P}$-labeled siRNA insulin $-h I D E$ sequence in the Southern blot analysis (Fig. 2B). The Southern blot analysis revealed that the copy numbers of the integrated transgenes varied from line to line, ranging from 3 to 12 copies. The first lineage founder mouse (\#9381) containing 6 copies of the H1/ siRNA $A_{\text {insulin }}-C M V / h I D E$ gene was selected for further study. The founder mice containing $s i R N A_{\text {insulin }}$ and $h I D E$ were then backcrossed to the $\mathrm{C} 57 \mathrm{BL} / 6$ parental strain in order to establish independent lines. The introduced siRNA $A_{\text {insulin }}$ and hIDE gene in their genomes was transmitted to all offspring with approximately $50 \%$ hemizygotes in a Mendelian fashion.

Tissue-specific regulations of siRNA $A_{\text {insulin }}$ and $h I D E$ expression in the $T g$ mice. In order to determine if the regulation of the introduced siRNA $A_{\text {insulin }}$ and $h I D E$ genes were expressed under the control of the $\mathrm{H} 1$ and CMV promoter in all tissues, the transcriptional levels of IDE and siRNA ${ }_{\text {insulin }}$ 
A

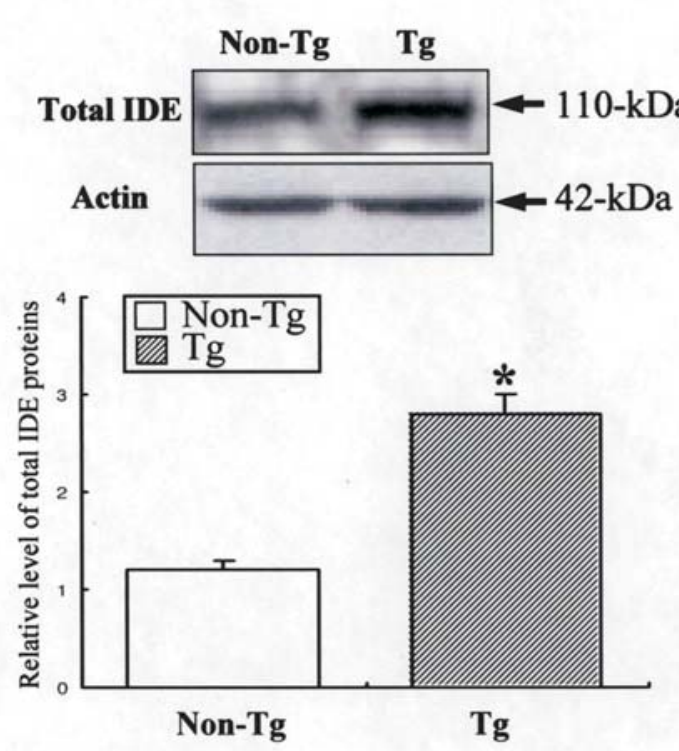

B

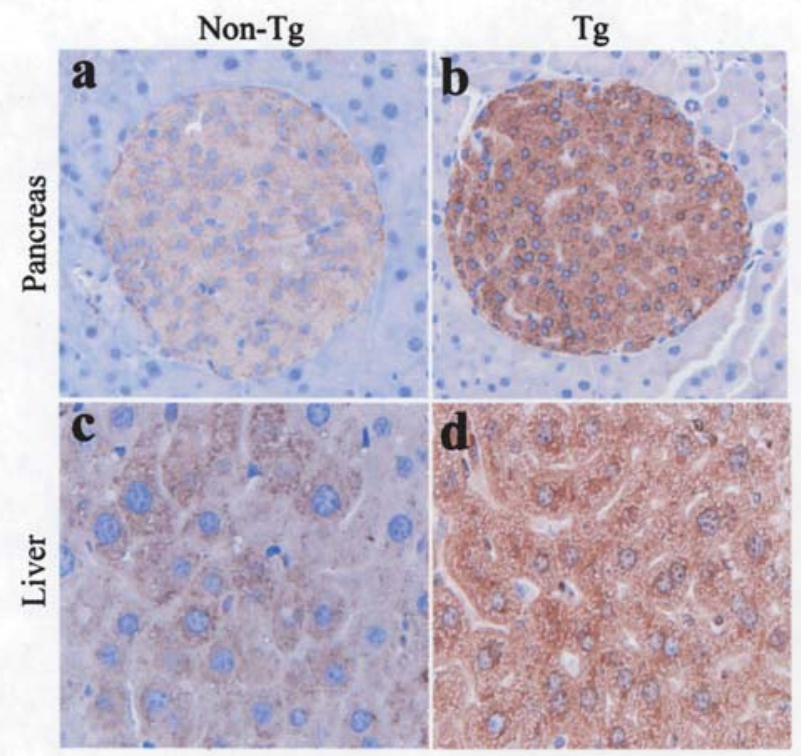

Figure 4. The level of IDE protein expression in the liver and pancreas. (A) Expression of the total IDE protein according to Western blot analysis. The membranes were incubated with the antibodies for IDE and the $\beta$-actin protein from the liver cytosol fraction. These antibodies were recognized by the IDE protein originating from the mouse and the human. Three mice/ group were assayed by Western blotting. The values are reported as a mean $\mathrm{SD}, \mathrm{p}<0.05$ vs control. (B) Immunostaining analysis of IDE expression. The expression profile of IDE in the liver and the pancreas at 20 weeks of age by immunostaining analysis. A high intensity was observed in the liver (B-c and B-d) and pancreas (B-a, and B-b) of the H1/siRNA insulin $-\mathrm{CMV} / \mathrm{hIDE} \mathrm{Tg}$ mice compared to the Non-Tg mice, at x200 magnification. The data represent the mean \pm SEM from three replicates. ${ }^{*} \mathrm{p}<0.05$, significant difference between treatments.

from various tissues including the brain, heart, lung, liver, kidney, intestine, and muscle of $\mathrm{H} 1 / \mathrm{siRNA}_{\text {insulin }}-\mathrm{CMV} / \mathrm{hIDE}$ Tg mice were examined by RT-PCR and real-time PCR analysis. In the RT-PCR analysis, the highest hIDE and siRNA $_{\text {insulin }}$ expression level was observed in the muscles, followed by the lung, brain, heart, liver, kidney, and intestine (Fig. 3A). Real-time PCR analysis showed a significantly higher level of the hIDE and siRNA insulin $_{\text {transcripts (RQ }}$

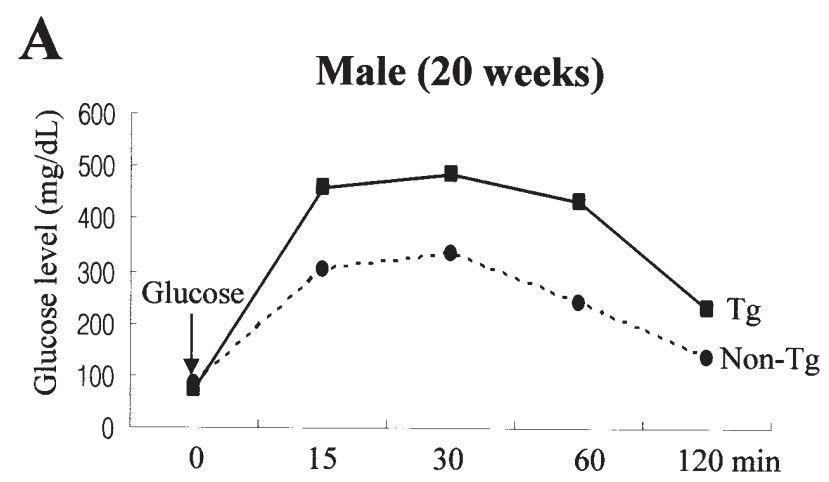

\section{B \\ Female (20 weeks)}



Figure 5. Post-prandial intraperitoneal glucose tolerance response. The serum glucose level in the IPGT test was monitored over time after an I.P. injection of glucose $(2 \mathrm{~g} / \mathrm{kg} \mathrm{BW})$. There was a difference in the glucose level between the two groups $15 \mathrm{~min}$ after the injection. Five mice/group were assayed in the IPGT test. The data represents the mean \pm SEM from three replicates. ${ }^{*} \mathrm{p}<0.05$, significant difference between treatments.

level) in the muscle and liver of the $\mathrm{H} 1 / \mathrm{siRNA}_{\text {insulin }}-\mathrm{CMV} /$ hIDE-Tg mice (Fig. 3B). Furthermore, total IDE protein expression in the liver of the $\mathrm{Tg}$ mice was examined using Western blotting and immunostaining in order to determine if the CMV-controlled hIDE proteins from the livers of the $\mathrm{Tg}$ mice stably expressed the IDE proteins. As shown in Fig. 4A, the total IDE proteins $(110 \mathrm{kDa})$ were detected by Western blotting using the specific antibody for mouse/human IDE proteins in the liver tissue of the H1/siRNA insulin CMV/hIDE $\mathrm{Tg}$ mice. The level of the IDE proteins was significantly higher in the liver and pancreas of the Tg mice than of the Non-Tg mice. In contrast, a very low level of the endogenous mouse IDE protein was detected in the Non-Tg mice (Fig. 4A). The IDE immunoreactivity in the liver was next analyzed using optical microscopy. The immunostaining intensity in the $\mathrm{H} 1 / \mathrm{siRNA}_{\text {insulin }}-\mathrm{CMV} / \mathrm{hIDE} \mathrm{Tg}$ mice was found to be spread throughout all regions of the liver (Fig. 4B-d) as a result of IDE immunoreactivity. However, the level of intensity in the Non-transgenic littermates was slightly lower than those of the Tg mice (Fig. 4B-c). Moreover, the islet cells in the pancreas were intensively immunostained in the H1/siRNA insulin $^{-}$ $\mathrm{CMV} / \mathrm{hIDE} \mathrm{Tg}$ mice, while these regions in the Non-Tg mice showed diffused immunoreactivity (Fig. 4B-a and b). Therefore, these observations suggest that the regulatory sequence of the hCMV early promoter is successfully attributed to the synthesis of the IDE protein in the H1/ siRNA $_{\text {insulin }}-\mathrm{CMV} / \mathrm{hIDE}$ Tg mice. 


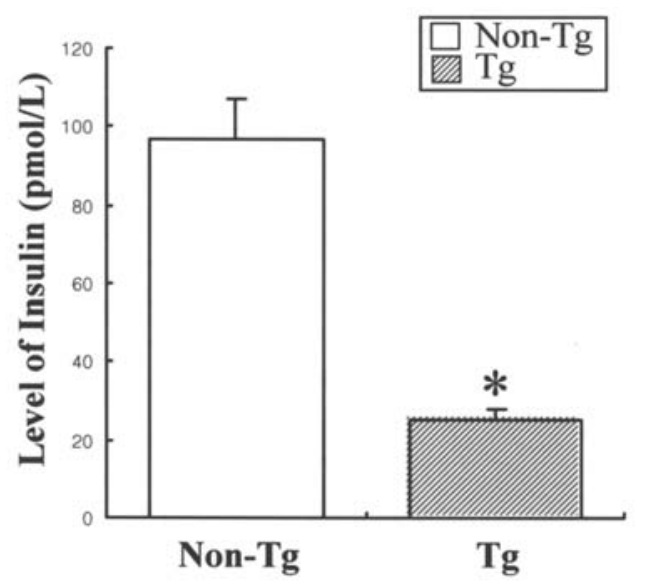

Figure 6. ELISA detection of the serum insulin level. Blood was collected from the abdominal veins of the $\mathrm{Tg}$ and Non-Tg mice. The insulin level was determined using an insulin ELISA kit (Mercodia, Sweden). The data represent the mean \pm SEM from three replicates. ${ }^{*} \mathrm{p}<0.05$, significant difference between treatments.

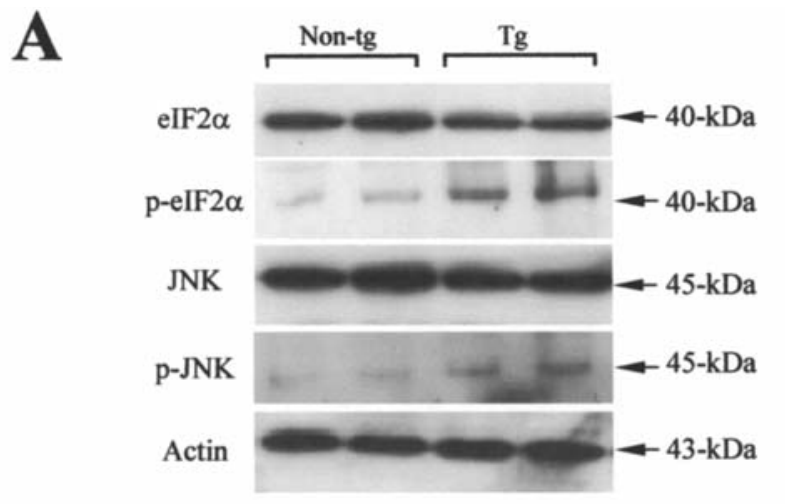

B

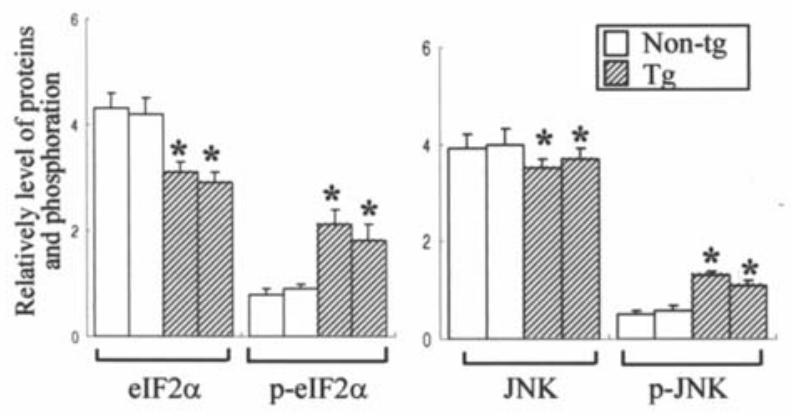

Figure 7. Activation of eIF2 $\alpha$ and JNK protein in the ER stress signaling pathway. Fifty micrograms of the protein/sample were immunoblotted with the antibodies for eIF $2 \alpha$, p-eIF $2 \alpha$, JNK, p-JNK and actin, respectively. Three experiments were assayed in triplicate using Western blotting. The values are mean $\pm \mathrm{SD}$.

Post-prandial intraperitoneal glucose tolerance response in the $T g$ mice. The effect of the siRNA insulin $_{\text {and hIDE }}$ overexpression in all tissues of the $\mathrm{Tg}$ mice on the glucose tolerance response was determined by measuring the serum glucose level during the time course of an IPGTT in the H1/siRNA insulin -CMV/hIDE Tg mice aged 20 weeks using a post-prandial intraperitoneal glucose tolerance test. The H1/siRNA insulin $-\mathrm{CMV} / \mathrm{hIDE} \mathrm{Tg}$ mice showed significant impairment in glucose tolerance during the course of an IPGTT (Fig. 5). In particular, the Tg mice aged 20 weeks showed a greater impairment of glucose tolerance than their Non-Tg counterparts with a higher difference being observed in the male $\mathrm{Tg}$ mice (Fig. 5A). These results suggest that $\mathrm{H} 1 / \mathrm{siRNA}_{\text {insulin }}-\mathrm{CMV} / \mathrm{hIDE} \mathrm{Tg}$ mice at this age have a lower insulin activity.

Suppression of serum insulin in the Tg mice. In order to verify the suppression of insulin production by the overexpressed siRNA $_{\text {insulin }}$ and hIDE protein, the serum insulin level was assayed in the H1/siRNA insulin -CMV/hIDE Tg mice using ELISA with the anti-insulin antibody. The serum insulin level was significantly lower in the H1/siRNA insulin $^{-C M V / ~}$ hIDE Tg mice than in the Non-Tg mice (Fig. 6). Therefore, the overexpressed $\operatorname{siRNA}_{\text {insulin }}$ and hIDE protein can effectively suppressed insulin production in the pancreas and stimulated insulin degradation in the liver of the $\mathrm{Tg}$ mice.

Changes in the proteins in the ER stress signal pathway. ER stress is significantly stimulated by glucose or nutrient deprivation, viral infection, lipids, increased synthesis of secretory proteins and expression of mutant or misfolded protein $(27,28)$. To examine whether ER stress was increased in $\mathrm{H} 1 / \mathrm{siRNA}_{\text {insulin }}-\mathrm{CMV} / \mathrm{hIDE} \mathrm{Tg}$ mice, the expression patterns of several molecular indicators of ER stress were detected using specific antibodies in the liver tissues from $\mathrm{Tg}$ mice. The level of p-eIF $2 \alpha$ protein was significantly increased in the Tg mice compare to the Non-Tg mice, indicating that the $\mathrm{Tg}$ mice were involved in the phosphorylation of the p-eIF $2 \alpha$ signaling system (Fig. 7). In addition, the Tg mice showed a significantly higher phosphorylation of JNK protein in the liver than Non-Tg mice. Therefore, these results suggest that decreased insulin and glucose impairment in the Tg mice can effectively induce the activation of JNK and eIF $2 \alpha$ proteins in the ER stress signaling pathway.

\section{Discussion}

Type 1 diabetes mellitus, accounting for the early onset of diabetes in children, is characterized by the down-regulation of insulin secretion in the pancreas, lower circulating insulin levels, and subsequently reduced insulin action on glucose uptake in the peripheral tissues and the liver. With an overall aim of developing model animals for type 1 diabetes, this study examined whether or not the suppression by the transgene-based siRNA ${ }_{\text {insulin }}$ sequence and the degradation as a result of the overexpression of the hIDE protein in $\mathrm{Tg}$ mice could contribute to a decrease in the level of circulating insulin and insulin action in vivo. Hasuwa et al (25) reported that transgenically supplied short duplex siRNA (21-23 nt) could silenced the ubiquitously overexpressed green fluorescent protein and simultaneously enhanced the expression of the red fluorescent protein in every tissue of $\mathrm{Tg}$ mice and rats. This suggests that this dual expression system may be an alternative method for the simultaneous gene disruption and overexpression in the same animals. In the present study, two 
insulin related genes, insulin siRNA and hIDE, were introduced into this dual expression system with the aim of developing a new diabetes-related model. Most studies have demonstrated that IDE is the primary enzyme for initiating cellular insulin degradation. This protein has a major role in insulin-degradation in cell homogenates (29). The features of cellular insulin degradation including the effects of various modifiers (e.g. $\mathrm{Ca}^{++}$) and inhibitors (e.g. bacitracin and Nethylmaleimiede) are consistent with the properties of IDE. However, the successful expression of the human IDE gene in a transgenic animal has not been reported. In this study, the hIDE gene and insulin siRNA sequence were applied to this dual expression system for overexpression in transgenic mice. Furthermore, the 5 types of siRNA sequences with specific binding to the insulin sequence were synthesized using the siRNA target finder program (Ambion) and inserted into the pSilencer 3.1 vector containing the $\mathrm{H} 1$ promoter, which successfully regulated the siRNA sequence both in vtiro and in vivo (30). The level of insulin in the cultured transfectants was significantly lower in the 1-1 and 2-2 clones of the $\mathrm{pH} 1 / \mathrm{siRNA}_{\text {insulin }}-\mathrm{CMV} / \mathrm{hIDE}$ transfectants than in the pEGFPC- 1 control transfectants (31).

The dual expression system containing siRNA insulin $_{\text {under }}$ the control of the $\mathrm{H} 1$ promoter and the hIDE cDNA under the control of the CMV promoter was expressed successfully in all tissues of the H1/siRNA insulin -CMV/hIDE Tg mice at the RNA level. In particular, the highest hIDE and insulin siRNA expression level was observed in the muscle, followed by the lung, brain, heart, liver, kidney, and intestine. There was also a significantly higher level of the total hIDE proteins in the liver in the $\mathrm{Tg}$ mice than in the Non-Tg mice used as the control, as indicated by Western blotting and immunostaining. Therefore, this dual expression system coexpressing the insulin siRNA and hIDE genes was successfully introduced into the genomic DNA of the Tg mice, which expressed the RNA and protein for down-regulating the insulin level in the $\mathrm{Tg}$ mice for the first time.

An impaired glucose tolerance and $\beta$-cell function are widely recognized as features of type 1 diabetes $(32,33)$. The animal models used for diabetic study were the Non-obese diabetic (NOD) mouse and the bio-breeding rat (34). The NOD mice discovered in Japan in the late 1970's (35) were inbred and distributed worldwide to establish numerous colonies. These colonies differ widely in the frequency and the age of onset of insulin-dependent diabetes mellitus (IDDM, 36), owing to various environmental factors. The onset of IDDM in NOD mice usually appears between 4 and 6 months of age, much more frequently in females than in males. In addition to diabetes, NOD mice developed thyroiditis (37), sialitis, and autoimmune hemolytic anemia late in life (38). Until now, numerous studies suggest that NOD mice are suitable models for investigating diabetes and its related disease. This study investigated whether or not the down-regulation of insulin production by insulin siRNA and hIDE overexpression could induce an impairment of glucose tolerance in the Tg mice. The H1/siRNA ${ }_{\text {insulin }}{ }^{-C M V / ~ h I D E ~ T g ~}$ mice at 20 weeks showed significant impairment in glucose tolerance during the time course of the IPGTT. Furthermore, the level of insulin in the serum of these $\mathrm{Tg}$ mice was significantly lower than in the Non-Tg mice, but slightly higher than typical NOD models. Therefore, the reduced insulin level by coexpressing insulin siRNA and hIDE could effectively induce an impairment of glucose tolerance.

The ER, a membranous network that functions in the synthesis and processing of secretory and membrane protein, was reported to play a key role in the response to cellular stress (39). It was reported that some stress conditions involved in the disruption of ER homeostasis led to the accumulation of unfolded or misfolded proteins in the ER lumen $(40,41)$. In this study, we investigated the effects of decreased insulin and glucose impairment on the expression of several molecular indicators of ER stress in the liver of $\mathrm{Tg}$ mice. In the various signaling pathways of ER stress, the proteins associated with the eIF $2 \alpha$ and JNK signaling mechanism were significantly activated in the Tg mice. Thus, our observations indicate that decreased insulin and glucose impairment in the Tg mice effectively induce the JNK and eIF2 $\alpha$ signaling pathway.

Hasuwa et al (25) first established the dual expression system containing the RNAi gene and the overexpressed gene in $\mathrm{Tg}$ mice. In their study, the transgenically supplied

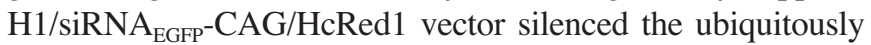
expressed green fluorescent protein while significantly increasing the red fluorescent protein in $\mathrm{Tg}$ mice. In the present study, the dual expression system was applied to the development of a novel diabetes-related model using the simultaneous overexpression of the insulin siRNA and hIDE genes. The insulin siRNA and hIDE genes were strongly expressed in various tissues of the H1/siRNA insulin $-\mathrm{CMV} / \mathrm{hIDE}$ Tg mice at both the RNA and protein level. In addition, these Tg mice were shown to have a diabetes-like phenotype such as an impaired glucose tolerance and decreased serum insulin level. Therefore, these results suggest that this dual expression system will be a useful tool for the development of novel animal models.

The H1/siRNA insulin $-\mathrm{CMV} / \mathrm{hIDE} \mathrm{Tg}$ mice can serve as an animal model manifesting type 1 diabetes-like phenotype. However, in order to understand type I diabetes mellitus, the physiological characteristics of the $\mathrm{Tg}$ mice need to be determined because these $\mathrm{Tg}$ mice may be used to examine the entire insulin-related metabolism in comparison with chemically-induced diabetic model animals.

\section{Acknowledgements}

The authors wish to acknowledge both B.S., S.M. Choi and M.S., M.K. Jang, animal technicians for directing the Animal Facility and Care at the Laboratory Animal Resources Team. This research was supported by a grant from the Scientific Research of the Korean FDA.

\section{References}

1. Duckworth WC, Bennett RG and Hamel FG: Insulin degradation: progress and potential. Endocr Rev 19: 608-624, 1998.

2. Seta KA and Roth RA: Overexpression of insulin degrading enzyme: cellular localization and effects on insulin signaling. Biochem Biophys Res Commun 231: 167-171, 1997.

3. Vekrellis K, Ye Z, Qiu WQ, Walsh D, Hartley D, Chesneau V, Rosner MR and Selkoe DJ: Neurons regulate extracellular levels of amyloid beta-protein via proteolysis by insulindegrading enzyme. J Neurosci 20: 1657-1665, 2000. 
4. Kirschner RJ and Goldberg AL: A high molecular weight metalloendopeptidase from the cytosol of mammalian cells. J Biol Chem 258: 967-976, 1983.

5. Muller D, Baumeister H, Buck F and Richter D: A trial natriuretic peptide (ANP) is a high-affinity substrate for rat insulin-degrading enzyme. Eur J Biochem 202: 285-292, 1991.

6. Garcia JV, Gehm BD and Rosener MR: An evolutionarily conserved enzyme degrades transforming growth factor-alpha as well as insulin. J Cell Biol 109: 1301-1307, 1989.

7. Gehm BD and Rosner MR: Regulation of insulin, epidermal growth factor, and transforming growth factor-alpha levels by growth factor-degrading enzymes. Endocrinology 128: 1603-1610, 1991 .

8. Muller D, Schulze C, Baumeister H, Buck F and Richter D: Rat insulin-degrading enzyme: cleavage pattern of the natriuretic peptide hormones ANP, BNP, and CNP revealed by HPLC and mass spectrometry. Biochemistry 31: 11138-11143, 1992.

9. Safavi A, Miller BC, Cottam L and Hersh LB: Identification of gamma-endorphin-generating enzyme as insulin-degrading enzyme. Biochemistry 35: 14318-14325, 1996.

10. Bennett RG, Duckworth WC and Hamel FG: Degradation of amylin by insulin-degrading enzyme. J Biol Chem 275: 36621-36625, 2000.

11. Mukherjee A, Song E, Kihiko-Ehmann M, Goodman JP Jr, Pyrek JS, Estus S and Hersh LB: Insulysin hydrolyzes amyloid beta peptides to products that are neither neurotoxic nor deposit on amyloid plaques. J Neurosci 20: 8745-8749, 2000.

12. Chesneau V, Vekrellis K, Rosner MR and Selkoe DJ: Purified recombinant insulin-degrading enzyme degrades amyloid betaprotein but does not promote its oligomerization. Biochem $\mathrm{J}$ 351: 509-516, 2000.

13. Edbauer D, Willem M, Lammich S, Steiner H and Haass C: Insulin-degrading enzyme rapidly removes the beta-amyloid precursor protein intracellular domain (AICD). J Biol Chem 277: 13389-13393, 2002.

14. Kupfer SR, Wilson EM and French FS: Androgen and glucocorticoid receptors interact with insulin degrading enzyme. J Biol Chem 269: 20622-20628, 1994.

15. Duckworth WC, Bennett RG and Hamel FG: A direct inhibitory effect of insulin on a cytosolic proteolytic complex containing insulin-degradation: progress and multicatalytic proteinase. J Biol Chem 269: 24575-24580, 1994.

16. Hannon GJ: RNA interference. Nature 418: 244-251, 2002.

17. Hutvagner $\mathrm{G}$ and Zamore PD: RNAi: nature abhors a doublestrand. Curr Opin Genet Dev 12: 225-232, 2002.

18. Fire A, Xu S, Montgomery MK, Kostas SA, Driver SE and Mello CC: Potent and specific genetic interference by doublestrand RNA in Caenorhabditis elegans. Nature 391: 806-811, 1998.

19. Bernstein E, Caudy AA, Haummond SM and Hannon GJ: Role for a bidentate ribonuclease in the initiation step of RNA interference. Nature 409: 363-366, 2001.

20. Gil $\mathrm{J}$ and Esteban M: Induction of apoptosis by the dsRNAdependent protein kinase (PKR): mechanism of action. Apoptosis 2: 107-114, 2000.

21. Elbashir SM, Harborth J, Lendeckel W, Yalcin A, Weber K and Tuschl T: Duplexes of 21-nucleotide RNAs mediate RNA interference in cultured mammalian cells. Nature 24: 494-498, 2001.

22. Brummelkamp TR, Bernards R and Agami R: A system for stable expression of short interfering RNAs in mammalian cells. Science 296: 550-553, 2002.
23. Lee NS, Dohjima T, Bauer G, Li H, Li MJ, Ehsani A, Salvaterra P and Rossi J: Expression of small interfering RNAs targeted against HIV-1 rev transcripts in human cells. Nat Biotechnol 20: 500-505, 2002

24. Yu JY, DeRuiter SL and Turner DL: RNA interference by expression of short-interfering RNAs and hairpin RNAs in mammalian cells. Proc Natl Acad Sci USA 99: 6047-6052, 2002.

25. Hasuwa H, Kaseda K, Einarsdottir T and Okabe M: Small interfering RNA and gene silencing in transgenic mice and rats. FEBS Lett 532: 227-230, 2002.

26. Kim YH, Kim S, Kim KA, Yagita H, Kayagaki N, Kim KW and Lee MS: Apoptosis of pancreatic beta-cells detected in accelerated diabetes of NOD mice: no role of Fas-Fas ligand interaction in autoimmune diabetes. Eur J Immunol 29: 455-465, 1999.

27. Ma Y and Hendershot LM: The unfolding tale of the unfolded protein response. Cell 107: 827-830, 2001.

28. Kaufman RJ, Scheuner D, Schroder M, Shen X, Lee K, Liu CY and Arnold SM: The unfolded protein response in nutrient sensing and differentiation. Nat Rev Mol Cell Biol 3: 411-421, 2002.

29. Akiyama H, Yokono K, Shii K, Ogawa W, Taniguchi H, Baba S and Kasuga M: Natural regulatory mechanisms of insulin degradation by insulin degrading enzyme. Biochem Biophys Res Commun 170: 1325-1330, 1990

30. Baer M, Nilsen TW, Costigan C and Altman S: Structure and transcription of a human gene for H1RNA, the RNA component of human RNase P. Nucleic Acids Res 18: 97-103, 1990.

31. Hwang DY, Oh JH, Kim YK, Shim SB, Jee SW, Lee SH, Seo SJ, Song YS, Nam KT, Cho JY, Hwang J, Jang IS and Cho JS: The overexpression of insulin-siRNA and insulin degrading enzyme decrease insulin levels in vitro and in vivo. Lab Anim Res 21: 96-104, 2005.

32. Kahn SE: Clinical review 135: The importance of beta-cell failure in the development and progression of type 2 diabetes. J Clin Endocrinol Metab 86: 4047-4058, 2001.

33. Pratley RE and Weyer C: The role of impaired early insulin secretion in the pathogenesis of type II diabetes mellitus. Diabetologia 44: 929-945, 2001.

34. Serreze DV and Chen YG: Of mice and men: use of animal models to identify possible interventions for the prevention of autoimmune type 1 diabetes in humans. Trends Immunol 26: 603-607, 2005.

35. Makino S, Kunimoto K, Muraoka Y, Mizushima Y, Katagiri K and Tochino Y: Breeding of a non-obese, diabetic strain of mice. Exp Anim 29: 1-13, 1980

36. Pozzilli P, Signore A, Williams AJ and Beales PE: NOD mouse colonies around the world: recent facts and figures. Immunol Today 14: 193-196, 1993.

37. Bernard NF, Ertug F and Margolese H: High incidence of thyroiditis and anti-thyroid autoantibodies in NOD mice. Diabetes 41: 40-46, 1992.

38. Baxter AG and Mandel TE: Hemolytic anemia in non-obese diabetic mice. Eur J Immunol 21: 2051-2055, 1991.

39. Berridge MJ: The endoplasmic reticulum: a multifunctional signaling organelle. Cell Calcium 32: 235-249, 2002.

40. Mori K: Tripartite management of unfolded proteins in the endoplasmic reticulum. Cell 101: 451-454, 2000.

41. Harding HP, Calfon M, Urano F, Novoa I and Ron D: Transcriptional and translational control in the mammalian unfolded protein response. Annu Rev Cell Dev Biol 18: 575-599, 2002. 